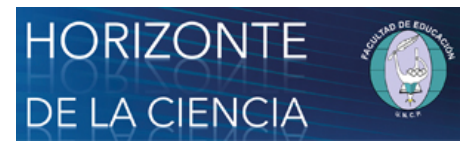

Horizonte de la Ciencia

ISSN: 2413-936X

horizontedelaciencia@uncp.edu.pe

Universidad Nacional del Centro del Perú

Perú

\title{
Las rondas campesinas del Perú una alternativa de justicia en las zonas rurales alto andinas, el caso de Ocongate un distrito rural del departamento del cusco 1992-2011
}

\author{
Chillihuani Ttito, Valentin \\ Las rondas campesinas del Perú una alternativa de justicia en las zonas rurales alto andinas, el caso de \\ Ocongate un distrito rural del departamento del cusco 1992-2011 \\ Horizonte de la Ciencia, vol. 10, núm. 18, 2020 \\ Universidad Nacional del Centro del Perú, Perú \\ DOI: https://doi.org/10.26490/uncp.horizonteciencia.2020.18.399
}

Los autores otorgan el permiso a compartir y usar su trabajo manteniendo la autoría del mismo. Atribución no comercial (CC BY-NC) 4.0 


\section{Las rondas campesinas del Perú una alternativa de justicia en las zonas rurales alto andinas, el caso de Ocongate un distrito rural del departamento del cusco 1992-2011}

The peasant rounds of Peru an alternative of justice in the high Andean rural zones, the case of Ocongate a rural district of the department of Cusco 1992-2011

As patrulhas camponesas do Peru uma alternativa de justiça nas zonas rurais alto andinas, o caso de Ocongate, um distrito rural do departamento de Cusco, 1992-2011

Piruchu muyupa nunakuna huk kamachiku kalu hana ulumalkakunachu,Ocongate distrituchunu kalu distritu

Cusco suyuchu 1992-2011wata

IBAIROPERO NAMPITSIPE KOBAPEROTACHARI ASHI PERU KISAKOBENTYARONERI

IROPERORI OBASANKETANTSI , INAMPITSIJEITE KATONKOSATSIPAYENI OKEMITATYA

OCONGATE APARONI NAMPITSIPERO ASHI NAMPITSIPE CUSCO. IRINKA TINSHEKI TIN TSA

PITE - PITE IRINKA TSA PANI

Ora ogerijenga kara timagantsipagekë Perukë iroro kara jirai otigobentagekeri ira timaigatsi Katsingagiteripagekë, jitacha Okongate timagantsi inatsi kara timagerontsi Cosco, osarini 1992-2011

Valentin Chillibuani Ttito Datos del autor

Universidad Nacional de San Antonio Abad del Cusco,

DOI: https://doi.org/10.26490/

Perú uncp.horizonteciencia.2020.18.399

valentin722@hotmail.com

(iD http://orcid.org/0000-0002-2672-6032

Recepción: 02 Junio 2019

Aprobación: 19 Julio 2019

Recepción: 02 Junio 2019

Aprobación: 19 Julio 2019

\section{Resumen:}

Las rondas campesinas son organizaciones rurales formados en el departamento de Cajamarca posteriormente se expandieron hacia el sur en los años de 1970, partiendo de este escenario nacional el presente trabajo presentará el estudio de las rondas campesinas de Ocongate, situado en la provincia de Quispicanchis, región Cusco, en la región sur andina del Perú. La presente investigación analiza y describe el ejercicio de la justicia comunal practicada en el distrito de Ocongate, desde sus orígenes hasta los momentos más actuales, en ello explora la compleja relación que mantiene con las instituciones representativas del gobierno nacional a nivel local. Palabras Clave: Comunidad campesina, Justicia, Rondas campesinas, Derecho consuetudinario, Abigeato, apatokitantsi nampitsipe, ibairopero nampitsi kobaperotachari, obasanketantsi amonkarateri ayoyetsiri, coshitatsiri piratsipe, Chakla ayllukuna, kamachiy, muyupa nunakuna, kikin nunakunap kamachikuyninkuna, uywasuwa, Timagantsigite birakochasikë, kantëgotagantsi, magetanerijegi, kantëgotagantsipage aike kosirintigite.

\section{Abstract:}

The peasant rounds are rural organizations formed in the department of Cajamarca subsequently expanded to the south in the 1970s, starting from this national scenario the present work will present the study of the peasant rounds of Ocongate, located in the province of Quispicanchis, region Cusco, in the southern Andean region of Peru. The present investigation analyzes and describes

\section{NotAS DE AUTOR}

Datos Valentin Chillihuani Ttito. Magister en Historia con mención en Estudios Andinos por la Pontificia Universidad Católica del Perú, docente de del autorla escuela profesional de Historia facultad de Derecho y Ciencias Sociales y docente de la escuela de Postgrado de la Universidad Nacional de San Antonio Abad del Cusco.

valentin722@hotmail.com 
the exercise of communal justice practiced in the district of Ocongate, from its origins to the most current moments, in it explores the complex relationship that it maintains with the representative institutions of the national government at the local level.

Keywords: Peasant Community, Justice, Peasant Rounds, Customary Law, Abigeato.

Palavras chave: Comunidade camponesa, justiça, rodadas camponesas, dreito consuetudinário, abigeato

\section{Antecedentes de las rondas campesinas del Perú y de Ocongate}

\section{A. Las rondas campesinas en el Perú}

Las rondas campesinas se fundaron en el caserío de Cuyumalca Chota-Cajamarca a mediados de los años 1970. Sin embrago, las rondas campesinas tienen antecedentes en las llamadas rondas de hacienda, que, según la obra de Pérez (1996) habrían tenido su aparición en los años 1920 y habrían subsistido hasta la desaparición de las haciendas. Además, revisa dos puntos de vista contra puestos. Por un lado, sostiene que la Federación de Campesinos de Chota eran rondas de hacienda, es decir, una institución para defender el poder económico y político de los hacendados; mientras que la investigadora Bonifaz (1986) plantea que las rondas de hacienda servían para controlar el robo de animales brindándole seguridad a la explotación agropecuaria. Y un tercer punto de vista se halla en una tesis de la Universidad de Cajamarca, en la cual sus autores argumentan (José Pérez Mundaca, Telmo Rojas y John Gitlitz) que la función de las rondas de hacienda era solo el cuidado del ganado, por lo tanto, la ronda de hacienda es desarrollada exclusivamente en jalcas y potreros.

Otro tema además de la función de la ronda de hacienda es dilucidar quienes integraban estas instituciones. De acuerdo a Pérez (1996) los integrantes de las rondas de hacienda eran los arrendatarios más jóvenes, quienes eran capaces de sacrificar su bienestar individual al servicio del patrón.

Otros antecedentes de las actuales rondas campesinas son las rondas de caserío organizadas en estancias afines de los años 1950, en un periodo que aumentaba dramáticamente la intranquilidad en el campo, puesto que se había iniciado una gran oleada de tomas de tierras e invasiones contra las haciendas tradicionales. Asimismo, se encuentran los guardias volantes, igualmente se organizaron en la fase final de los cincuenta y comienzos de los años sesenta. Estas guardias volantes habrían sido constituidas por la policía y rondaban de noche zonas infectadas de abigeos.

\section{B. Bases legales de las rondas campesinas}

A continuación, vamos a contemplar cada una de las normas gubernamentales con relación a las rondas campesinas. En primer término, encontramos que en el primer gobierno del presidente Alan García, fue emitida una primara norma que constaba de un artículo único en el año 1986. Esta norma a la letra dice:

En este artículo único reconocen a las rondas campesinas como pacificas democráticas y autónomas, para la defensa de sus tierras, cuidado de su ganado y de más bienes, cooperando con las autoridades en la eliminación de cualquier delito. Dado en la casa de gobierno, en Lima, a los seis días del mes de noviembre de mil novecientos ochenta y seis (Berrio, 2004). Por otro lado, hacia 1989 la organización internacional del trabajo aprobó el convenio 169 sobre pueblo indígenas y tribales en países independientes el siete de junio de 1989, dicho convenio fue ratificado por el gobierno en el Perú en 1993 mediante la resolución legislativa N. 26253; a partir de este momento es ley en el Perú.

En su reunión número 76 , se precisó en varios artículos sobre la conservación de las tradiciones y costumbres de cada pueblo indígena, de esta manera cuando se imponga sanciones penales previstas por la legislación general a miembros de dichos pueblos deberán tenerse en cuenta sus características económicas, sociales y culturales (Marquez, 1994). 
Mientras tanto, en el Perú, la violencia terrorista alcanzaba niveles de gran magnitud conforme avanzaba la década de 1980. Por ello, la organización de las rondas contra la delincuencia se dio conectada con la organización de comités de autodefensa campesina, promovidos por las fuerzas armadas, contra las organizaciones terroristas de Sendero Luminoso y el MRTA. Por ello una nueva norma fue aprobada en 1991, normando la posesión y uso de armas por las rondas campesinas a través del decreto legislativo 740 (Berrio, 2004).

Por otro lado, la norma más controvertida fue promulgada en 1993, a través de un decreto supremo del Ministerio de Defensa disponiendo que las rondas campesinas adecuen su organización y funciones a los comités de autodefensa, los cuales están sujetos a las órdenes y dependen del ejército peruano. Este decreto buscaba controlar a las rondas que habían surgido en forma autónoma y su argumentación era la necesidad de desarrollar una sola política en el enfrentamiento contra Sendero. Este decreto supremo tiene dos artículos y fue promulgado por el presidente Fujimori el 15 d enero de 1993.

Después de la caída del régimen de Alberto Fujimori, el gobierno de Alejandro Toledo promulgó la Ley 27908, publicada el siete de enero de 2003, norma que le devuelve la autonomía a las rondas campesinas. El gestor de esta ley fue el entonces parlamentario Luis Guerrero. Ella consta de nueve artículos y establece el 29 de diciembre como el día jubilar de las rondas campesinas y señala al caserío de Cuyumalca como origen de estas instituciones en el Perú (Chillihuani, 2006).

\section{Las rondas campesinas en el distrito de Ocongate}

$\mathrm{Al}$ igual que en Cajamarca y otros lugares del Perú, la ronda campesina de Ocongate nace por la necesidad social de enfrentar a la delincuencia, que se presenta como una urgencia sentida en forma abrumadora, porque los malhechores estaban fuera de control y las autoridades del Estado central eran impotentes para contenerlos. Inclusive los delincuentes llegaron a cometer algunos crímenes que fueron el último estímulo para la formación de la ronda.

De acuerdo a la versión del padre Antonio Sánchez Guardamino Semante, hubo instituciones previas a la ronda que habían nacido para apoyar al campesinado y cuyas actividades constituyen los antecedentes necesarios de las rondas. El padre Antonio destaca a la ONG CCAIJO, nacida de la parroquia de Andahuaylillas bajo el liderazgo de la orden jesuita. Esta ONG fue fundada al comenzar los años 1970 y sus actividades se extendieron a Ocongate en 1976. Progresivamente se involucraron con las comunidades campesinas en labores de apoyo como cursos de capacitación sobre el manejo de camélidos sudamericanos, talleres sobre técnicas para el cultivo y manejo de semillas de productos agrícolas, tratamiento de pastos etc. La mencionada ONG funciona hasta el día de hoy, casi 40 años después de ser fundada.

Para ir completando nuestro análisis vamos a presentar la visión de un líder campesino fundador de las rondas a nivel distrital. Se trata del señor Julián Rojo Gonzalo, quien participó del grupo inicial de Ocongate y asimismo de otras experiencias similares en áreas rurales vecinas. En el año 2012 el señor Rojo ha cumplido 61 años, por lo tanto, comenzaba sus cuarenta años de edad cuando protagonizó la organización de las rondas. Rojo menciona que en las comunidades campesinas había personas denominadas personeros o cabecillas.

Estas personas ejercían la autoridad local y eran nombradas por los mismos comuneros de la zona a través del sistema de cargos, ascendiendo progresivamente en la escala como dirigente campesino. Estas autoridades estaban presentes en cada comunidad y anexo, eran quienes hablaban sobre conflicto de tierras y temas de robos o ladrones. El señor Rojo subraya que estas autoridades comunales luchaban contra los abusos que cometían los hacendados de Tinki Lauramarca, Ccapana y otras estancias. En el periodo de crisis final del régimen terrateniente oligárquico, estas autoridades comunales supieron viajar a Lima y hacer gestiones antes las autoridades del Estado, fueron eficientes intermediarios de los intereses comunales ante la crisis de la hacienda tradicional andina. Algunos de estos dirigentes que encabezaron las luchas de los años 1950 y 1960 todavía están vivos, como por ejemplo el señor Crispín de Upis, Sixto Flores y Luis Yupanqui de 
Puycabamba (Rojo, comunicación personal, 28 de agosto del 2008). A ello incluye al "Arariwa" personaje que cuida la chacra durante toda la temporada de sembrío. De este modo podemos sintetizar que en la historia organizativa de las comunidades campesinas de Ocongate, no había un cargo específico a nivel comunal para enfrentar temas de delincuencia.

Una comparación entre las rondas campesinas de Chota en Cajamarca con las rondas de Ocongate muestra una diferencia sustancial en cuanto a los personajes institucionales que habían antecedido en Cajamarca a las rondas. De acuerdo al padre Antonio Sánchez.

La práctica del abigeato venía ejerciéndose tiempo atrás, amparados en la oscuridad de la noche, a partir de los dos últimos años de la década de los ochenta se intensificó de manera alarmante. Y lo que es peor se introdujo la modalidad de asaltos en plena luz del día por grupos de hasta doce ó trece personas, a pie a caballo frecuentemente armados. (Guardamino, 1997, p. 6)

En este artículo el padre Antonio confirma que ante el aumento brusco de un problema social de envergadura el entramado social de Ocongate reacciona impulsando la formación de rondas como nueva organización social destinada a combatir un mal social especifico.

Durante los años 1988 y 1989 se agudizó el fenómeno del terrorismo a escala local y el ejército tomó la iniciativa de crear los comités de autodefensa para enfrentar a Sendero. Así mismo, hacía 1990 y 1991, conforme el terrorismo fue derrotado a escala local, el abigeato fue creciendo exponencialmente, entonces la parroquia empezó a tratar el tema de organización de rondas contra la delincuencia. En sucesivas reuniones de catequistas se madura la idea involucrando a las comunidades de Ocongate y distritos cercanos, como por ejemplo Carhuayo, Ccatcca y Marcapara, todos ellos de la provincia de Quispicanchis.

Don Toribio Mendoza Mamani, un dirigente campesino que fue miembro de la primera ronda campesina de Ocongate, manifiestó que la parroquia mando un oficio a todas las comunidades del distrito para llevar adelante una reunión en el mismo local parroquial, para la conformación de la primera dirigencia de la ronda campesina de Ocongate. Asistieron unas setenta u ochenta personas, mayormente eran líderes de las comunidades de Ocongate, que aprobaron en forma unánime la constitución de la ronda y eligieron la primera junta directiva.

Este grupo de líderes campesinos seleccionados en la parroquia decidió realizar una gran asamblea pública para formalizar la creación de la ronda y la elección de esta junta directiva. De este modo, al pie de la laguna Yanacocha, esto es las cercanías del nevado Ausangate, en fecha el 20 de agosto de 1992 se llevo adelante una gran asamblea, que los líderes campesinos denominan "hatun encuentro" que reunió unos cuatro mil campesinos de varios distritos de la provincia e incluso de Canchis. En esa reunión fueron presentados muchos ladrones de Ocongate y de Canchis, a quienes se sometió a disciplina, dicha acta de fundación se encuentra en el archivo regional de registros públicos de la región de Cusco.

\section{La violencia y la guerra interna}

De acuerdo a la versión del padre Antonio Sánchez Guardamino, la organización de la ronda campesina en Ocongate no se puede desligar del fenómeno del terrorismo que asolo al Perú en los años de 1980 y comienzos de 1990. Inclusive los mismos ladrones y abigeos eran denominados "terrucos", refiriéndose a los militantes de Sendero Luminoso. Los senderistas efectivamente no asaltaron ni robaron, pero su accionar creo el clima de inseguridad y desató una violencia que le dio alas a la delincuencia, los diversos robos que se cometían en nombre del terrorismo en la carretera Cusco-Quince mil por la zona de Huallahualla.

Asimismo, el Centro de Estudios Regionales Andinos Bartolomé de las Casas (CBC), puso en marcha en proyecto LUCCA, orientado a la lucha concertado contra el abigeato (CBC, 2005). En los documentos de este proyecto se subraya la afirmación de Telmo Rojas, quien ya había señalado la importante presencia de la Iglesia en la conformación de la ronda. Estos documentos también resaltan la participación de las ONGs, como el mismo CBC y sus diversos proyectos en la región Cusco (CBC, 2005). 
Por su lado, la ONG CCAIJO en alianza con IDL-Lima desarrollaron un manual sintetizando la experiencia inicial de la ronda campesina de Ocongate. Este manual fue muy importante en la organización del núcleo dirigente de las rondas; fue redactado por el abogado Jaime Márquez Calvo; incidiendo sobre todo en derechos humanos. La presencia de este manual expresa la importancia de los actores externos en la consolidación de los organismos campesinos a nivel local.

\section{E. Las autoridades locales y el surgimiento de las rondas}

Según el antropólogo Starn (1991) la corrupción de justicia estuvo presente también en Cajamarca, habría habido complicidad entre las autoridades estatales y la delincuencia. Peor aún, gracias a los sobornos y la mala práctica judicial, la mayoría de los delincuentes eran absueltos. En la provincia de Chota-Cajamarca, solo el $10 \%$ de los casos juzgados por abigeato fueron encontrados culpables y recibieron condenas. El otro $90 \%$ resulto absuelto.

Frente a esto, las ONGs CCAIJO, IDL y Casa campesina toman la iniciativa de capacitar a los dirigentes campesinos para que asuman sus derechos y puedan conducir una organización que aplica el derecho consuetudinario como base para la administración de justicia a nivel local (Libro de actas, 1995).

Por ejemplo, nuestro entrevistado don Julián Huamán Quispe, fundador de la ronda campesina de Ocongate manifiesta que la primera institución que se opuso a la organización de la ronda fue la Policía Nacional del Perú. Del mismo modo, el primer presidente de la ronda campesina don Julián Rojo nos indica que la policía se opuso a la ronda campesina, haciéndose presente en una de las asambleas llevada adelante en el lugar denominado Sillita, oponiéndose al castigo que la ronda acostumbrada dar a los abigeos. Una de las consecuencias de esta visita policial fue la detención del principal dirigente de las rondas, don Julián Rojo, quien fue golpeado en el puesto policial y denunciado ante el poder judicial (Rojo, comunicación personal, 28 de agosto del 2008). De la misma opinión es don Mariano Chillihuani, quien fue encerrado en el calabozo por denunciar la complicidad de las autoridades locales, que no hacían nada para superar la agobiante situación de inseguridad que se vivía debido al abigeato (Chillihuani, comunicación personal, 28 de septiembre del 2008). De este modo, se desarrolló un conflicto entre la organización campesina y la PNP.

Pero los jueces de paz de Quispicanchis vieron con malos ojos el surgimiento de la ronda campesina de Ocongate. De acuerdo al testimonio de don Toribio Mendoza Mamani, miembro fundador de la primera ronda campesina, los jueces de paz estaban coludidos con los abigeos, recibiendo regalos de parte de los ladrones para emitir sentencia a favor de la delincuencia (Mendoza, comunicación personal, 6 de septiembre del 2008). Otra apreciación del mismo tema se debe a don Hilario Quispe Mayo, quien ha sido presidente de la ronda campesina. Don Hilario sostiene que la oposición de los jueces de paz proviene de la competencia que sentía que las rondas ejercían sobre su propia misión. Es decir, para don Hilario Quispe el problema era que dos sistemas de autoridad trataban de imponer su criterio en el mismo ámbito. De acuerdo a esta versión, no se habría tratado necesariamente de colusión con los delincuentes, sino de competencia por el ejercicio de la autoridad local (Quispe, comunicación personal, 24 de septiembre del 2008).

Por su lado, el Gobernador es la autoridad de la Dirección General del Ministerio de Interior, representa al Presidente de la República y al poder ejecutivo a nivel local. Del mismo modo que en los casos anteriores, el gobernador y los tenientes gobernadores fueron hostiles al surgimiento de las rondas campesinas. De acuerdo al testimonio de don Julián Huamán Quispe (Huaman, comunicación personal, 8 de septiembre del 2008). Los "llaqta taytas" (traducción literal: los grandes padres de la ciudad) no quieren que una organización campesina prospere. Esto significa que el dirigente campesino interpreta la presencia de una contradicción que opone las autoridades citadinas contra la organización campesina. Según su lenguaje literal, son los grandes padres de la ciudad quienes no quieren organizaciones campesinas. Así, estaríamos ante una oposición entre el campo y la ciudad para la administración de justicia a nivel local. 


\section{F. Los encuentros de las rondas campesinas}

Las rondas campesinas de Ocongate se reúnen en asambleas de dos niveles. En el primer caso se trata de reuniones dentro de las comunidades campesinas, mientras que la segunda forma es una reunión intercomunal a nivel de todo el distrito. La magnitud de los delitos sancionados es uno de los grandes factores para determinar el tipo de reunión que habrá de evaluarlos.

En cada comunidad existe un comité especializado de rondas campesinas, que realiza actividades con sus integrantes estando dirigido por una junta directiva, compuesta por presidente, secretario, tesorero, fiscal y vocal. Adicionalmente se encuentran las guardias campesinas, quienes normalmente son comuneros jóvenes licenciados de las fuerzas armadas.

Las asambleas centrales de las rondas campesinas de todo el distrito son conocidas como Hatun encuentros (palabra quechua que significa encuentro grande). Estas reuniones son convocadas por la junta directiva central. Inicialmente era obligatoria la participación de todas las comunidades campesinas, pero posteriormente se aprobó que solo asista un grupo de delegados por comunidad que se encuentran a mayor distancia del lugar de las asambleas centrales, como por ejemplo los distritos de Marcapata, Quiquijana, Ccatcca y Carhuayo.

Otro punto es la amplitud de la ronda un Hatun encuentro excede al mismo distrito de Ocongate, puesto que acuden comuneros y rondas de otros distritos también. Un Hatun encuentro es una asamblea extraordinaria, convocada cuando hay un motivo preciso. Vale la pena mencionar que, en el estatuto de la ronda campesina que se encuentra en el cuaderno de actas de 1995, p. 41, no define la frecuencia con la que se deben llevar a cabo las plenarias, sin embargo, señala que las asambleas son ordinarias y extraordinarias (Libro de actas, año 1995, p. 41).

Un Hatun es un encuentro que siempre tiene como propósito ejercer punición sobre algún delincuente capturado. Muchas veces incluye baños de agua fría, por lo que se presta a una localización cerca de un río o laguna. Por su parte la comunidad anfitriona tiene que asistir íntegra, incluyendo mujeres y niños. Según don Toribio Mendoza, quien fue catequista de la parroquia de Ocongate, y estuvo fuertemente involucrado en la organización de las rondas, relata que había un esfuerzo consciente para que todo el mundo pueda observar el proceso de justicia campesina (Mendoza, comunicación personal, 6 de septiembre del 2008).

Asimismo, se puede observar la presencia de la bandera peruana flameando en una de las lomadas próximas al desarrolla y de la plenaria de rondas campesinas. Esas banderas simbolizan la pertenencia de las comunidades campesinas a la nación peruana, mostrando la combinación entre el sentimiento de autonomía local y la pertenencia a una sociedad nacional integrada al Estado peruano.

La cuota de género femenino está integrada por dos sub-secretarias, mientras que, en Cajamarca, la organización de mujeres ronderas incluye su propia junta directiva paralela a la de varones. Por ello están organizadas en la federación de rondas campesinas del norte del país FEROCAFENOP, que logró la institucionalidad de las rondas femeninas, que abarcan las regiones de Amazonas, Cajamarca y Lambayeque. Mientras que el sur, del Perú no se registra federación de mujeres de rondas campesinas.

Según Hilario Quispe Mayo, la junta directiva central de Ocongate está integrada por dos mujeres, una de la cuales es secretaria de asuntos femeninos y la siguiente es sub-secretaria. Esta afirmación fue contrastada con los cuadernos de actas de diferentes juntas directivas que incluyen este cargo a partir del año 1997 para adelante (Libro de actas, año 1996, p. 259). Este cargo coordina cualquier problema relacionado con las mujeres y las posibles sanciones por algún delito que puedan haber estado involucradas (Quispe, comunicación personal, 24 de septiembre del 2008). Si bien es cierto que en las entrevistas nos manifiestan que esta incorporación es reciente, sin embargo, se puede apreciar que en el estatuto de la ronda campesina de Ocongate en el cuaderno de actas de 1995, existe el puesto de secretaria de asuntos femeninos (Libro de actas, año 1995, p. 40). 
Las rondas campesinas procuran recuperar los objetos robados y en caso de no obtenerlos, la sanción incluye la reparación del daño causado al agraviado. Toribio Mendoza nos relata que todo lo recuperado es para quien fue víctima del robo y de ninguna manera los directivos no se quedan con ellos. Por lo tanto, la justicia campesina es honesta y rápida, diferenciándose de la lentitud y el trámite engorroso que caracteriza al sistema oficial de justicia (Quispe, comunicación personal, 6 de septiembre del 2008).

La sanción a los delincuentes es una parte importante de la vida de la ronda campesina, porque la punición pretende restablecer la normalidad y brindar seguridad a la vida campesina, alejando la delincuencia de las aldeas y comunidades. Por ello es que se castiga con esfuerzos físicos propios de la vida castrense, como carreras, planchas, ranas y canguros. Este tipo de castigos ha llevado a la investigadora Bonilla (1995) a preguntarse si expresa la militarización de las rondas campesinas.

Asimismo, otro castigo frecuente son los baños de agua fría, en ríos o lagunas. Los encargados de aplicar esta sanción son las guardias campesinas, quienes ejecutan inmediatamente los acuerdos de la asamblea. Si el delincuente es una mujer, entonces la asamblea encarga a una señora de respeto, que la introduzca al agua fría.

Los azotes con látigo son la tercera sanción que aplican las rondas campesinas. Normalmente las sanciones están ordenadas, empezando por los ejercicios físicos siguiendo por el baño de agua fría y terminando por los azotes. Estos no son aplicados por la guardia campesina, sino por una persona de prestigio, que es seleccionada especialmente para que el abigeo no sepa quién lo está azotando. Otro procedimiento es encargar a los familiares e incluso a los mismos padres del delincuente para que ellos sean quienes lo azoten. De este modo, se evitan posibles venganzas y resentimientos entre personas que normalmente siguen viviendo en las mismas comunidades.

Estas sanciones son ejecutadas a la vista del público asistente a la asamblea, conllevando a una fuerte humillación del delincuente, por lo tanto, reforzando su arrepentimiento. Porque la intención de los castigos es doble, tanto como recuperar lo robado como corregir al delincuente. De acuerdo al padre Antonio Sánchez, algunas sanciones le han parecido algo exageradas y declara que prefiere otro tipo de sanciones, como el trabajo social a favor de la comunidad, que se aplica extensamente entre los ronderos del norte del país (Guardamino, comunicación personal, 8 de octubre del 2008).

\section{Rondas De OCONGate a LA ACTUALIDAD}

\section{A. Situación de las rondas campesinas de Ocongate a la actualidad}

Las rondas campesinas inicialmente eran centralizadas por una junta directiva central, llamada la Central de Rondas Campesinas de Ocongate y Carhuayo, denominación con la que se inscribieron en los registros públicos. Ese nombre indicaba que confluyeron varios distritos, además de los mencionados tanto como Marcapata, Ccatcca, Paucartambo e incluso Quiquijana. (Libro de actas, 1995, p. 22). También participaban de la ronda, así consta en los diferentes libros de actas del año 1995 que hemos encontrado en los archivos de la central de rondas de Ocongate. Según nuestro entrevistado don Mariano Chillihuani, esta centralización fue muy necesaria en los inicios y fortaleció la institucionalidad gracias a su capacidad de convocatoria (Chillihuani, comunicación personal, 28 de septiembre del 2008).

Las rondas campesinas estuvieron centralizadas durante cuatro años, posteriormente empezaron a desmembrarse, puesto que cada distrito fue formando su propia central de rondas campesinas. Actualmente solo los comuneros de Carhuayo siguen participando con los de Ocongate, aunque también ha comenzado el proceso de separación en los últimos años. Esta tendencia a la fragmentación se ha profundizado, incluso al nivel del mismo distrito de Ocongate, puesto que ha aparecido la central de rondas campesinas de la margen derecha. Inclusive la ronda campesina de la comunidad de Accocunca se ha transformado en comités de autodefensa y continúa hasta el día de hoy con esa denominación. Ese nombre evidencia que esta organización 
ha desarrollado un lazo que la vinculas al ejército peruano y su esfuerzo por mantener relaciones con campesinos que garanticen la paz social en sus respectivas localidades.

Pero la mayor fragmentación ha venido acompañada por la capacidad de las rondas para asumir nuevas funciones. De acuerdo al testimonio del padre Antonio Sánchez.

Las rondas son las organizaciones más representativas de los campesinos de la zona. Están ya aceptadas en el conjunto social de Ocongate como una institución que tiene su peso propio y su palabra que decir; son un referente obligado del que no se puede prescindir. (Guardamino, 1997, p. 7)

Este prestigio social le ha permitido a la ronda ampliar sus funciones hasta abarcar problemas de índole familiar, como caso de violencia en el hogar, maltrato a las mujeres, situaciones de adulterio y hasta la muerte de un infante; así consta de acuerdo a algunos oficios que se logró hallar en los archivos de la central de rondas de Ocongate. Otras nuevas funciones son más políticas, como la organización de reuniones con los candidatos a la alcaldía del distrito para la exposición de sus propuestas; incluso se registran actividades en el tema del trasporte, por ejemplo, ha resuelto las tensiones entre la línea de trasportistas que ha aumentado sus operaciones a raíz de la construcción de la carretera interoceánica.

Por su parte, el comunero Julián Rojo precisa que la ronda también interviene en litigios en torno a terrenos de cultivo, resolviendo contradicciones entre comuneros e incluso entre comunidades (Gonzalo, comunicación personal, 28 de agosto del 2008). Sobre este mismo tema, el comunero Julián Huamán nos relata que las rondas campesinas se ha propuesto abarcar la mayor cantidad de temas, incluyendo los asuntos de concesiones mineras, involucrándose en la ley de consulta previa y los mecanismos que prevé para la concesión de licencia social.

Pero hay otras opiniones. Por ejemplo, el comunero Julián Huamán, considera que la ronda ha ido demasiado lejos y que hoy en día está algo confundida, discutiendo temas como la ley de aguas, para las cuales no están capacitadas. Según esta opinión, la multifuncionalidad seria causa de debilidad, porque la organización pierde sentido al no estar concentrada en su función principal y diluirse en una serie de temas que no son de su efectiva capacidad de resolución (Huamán, comunicación personal, 8 de septiembre del 2008).

Otro punto importante es la economía de las rondas, porque en principio la justicia campesina es gratuita y no se cobra por proceso judicial, como se realiza en la justicia ordinaria. Sin embargo, la ronda campesina necesita una base material para funcionar y con frecuencia ha apelado a las cuotas, que cada comunidad aporta para la caja de las rondas. Por ejemplo, hemos encontrado en el archivo de la ronda central numerosos documentos contables correspondientes al año 1994, 1995 y 1996 que dan fe del pago de cuotas por comunidad a la caja de las rondas (Libro de cajas, 1994).

Por otro lado, la justicia campesina ejercida por las rondas es expeditiva, ahorrándole al poblador campesino litigante los grandes trámites que implica la justicia formal. Esos trámites se redoblan debido a los viajes del expediente, que circulan del distrito a la provincia, obligando a gastos extras en servicios legales y abogados. Por ello, la justicia campesina de las rondas está al alcance del campesino común y corriente y le significa una forma más sencilla de resolver los conflictos reales.

En ese mismo sentido, opera el tema del idioma. En efecto, en el distrito de Ocongate el idioma inmensamente mayoritario es el quechua, mientras que todos los servicios legales del Estado peruano funcionan en español. De este modo, el funcionamiento de la ronda campesina en lenguas indígenas facilita su empleo por parte de la población rural como mecanismo privilegiado para resolver los litigios legales locales. El tema de la lengua conduce al de la cultura, porque no se trata solamente de un sistema legal que emplea el mismo idioma de los campesinos, sino que además la ronda campesina se funda sobre la identidad cultural con el mundo andino. Así, la ronda comparte la cosmovisión de los campesinos que acuden a ella. Lengua y cultura son poderosos refuerzos de la legitimidad de la ronda en el espacio distrital. 
Las ventajas de la ronda campesina para la aplicación de la justicia en espacios locales del mundo andino han sido enfatizadas por varios estudios, entre los cuales destaca la obra de la abogada Aranda (2004) según la autora, los elementos que hemos analizado se hallan presentes definiendo la eficiencia de la ronda, en contraste con la falta de capacidad del Estado para realmente resolver los temas judiciales en Ocongate. Adicionalmente, esta autora subraya la unidad que existe en la ronda entre los órganos de decisión y los de coacción.

Las sanciones que imparten las rondas campesinas consisten en la realización de esfuerzos físicos, baños de agua fría y castigos a latigazos. En contraste, las rondas campesinas de Cajamarca han empleado las faenas comunales obligatorias como mecanismo de sanción al campesino que ha delinquido. Pero, en Ocongate estas faenas no han sido empleadas, mayormente han sido castigos físicos, que el mismo padre Antonio Sánchez considera que ha sido algo crueles (Guardamino, comunicación personaL, 8 DE OCTUBRE DEL 2008).

Para el campesino don Julián Huamán, uno de los fundadores de la ronda, los baños de agua fría han sido empleados extensamente como el primer mecanismo de punición empleado por la ronda. Según su interpretación, los baños de agua fría, son una forma de renacimiento corporal simbólico, significando una forma de purificación. La procedencia cristiana y la presencia de numerosos catequistas refuerza la idea de símbolos cristianos de castigo y purificación como determinantes de la cultura judicial de las rondas.

Por su lado, el uso extensivo del látigo tiene dos explicaciones. Por un lado, es una prolongación de la forma de castigo habitualmente en el seno de la familia campesina. En efecto, ante los actos de desobediencia o mala conducta de parte de los hijos, los padres campesinos se encargan de castigarlos, empleando siempre violencia física y haciéndolo en nombre de Dios. Del mismo modo, las guardias campesinas están identificadas con los Pauluchas (Canal, 2001), quienes son los guardianes de la festividad del Señor de Qoylluriti, estos personajes son considerados como los intermediarios entre el Señor de Qoylluriti y los hombres, vestidos con un traje bastante parecidos al oso hecho de lana de alpaca. Por lo tanto, el castigado no siente que la guardia campesina lo haya maltratado, sino que ha aplicado una medida que proviene de lo alto. De este modo, la justicia rondera evita las reacciones de venganza contra los ejecutores de las sanciones acordadas.

Pero, el uso intenso del látigo guarda continuidad con las formas de castigo empleadas en las haciendas tradicionales. En efecto los hacendados guardaban el orden terrateniente regularmente empleando el látigo contra aquellos colonos que hubieran cometido una incorrección. Los campesinos eran reunidos en el patio de la hacienda y con el látigo era castigado el infractor, amedrentando al público. Así, el látigo tiene un doble origen, que se resume en su popularidad como mecanismo para el castigo en las zonas rurales.

De acuerdo a la interpretación de Orin Starn (1993), las rondas campesinas han ejercido punición sin reproducir las normas represivas de la hacienda o las fuerzas armadas del Estado. Por el contrario, las rondas han operado bajo la autoridad colectiva de la comunidad. Por ello, los mecanismos de punición que han empleado expresan la vinculación entre el organismo que toma la decisión de castigar y los encargados de llevarla a la práctica. La idea de Starn (1991) considera que las rondas campesinas cuando castigan toman las imágenes de autoridad y los mecanismos de sanción del pasado, pero proyectándolos a una nueva etapa, en tanto que son aplicadas por una autoridad colectiva de la comunidad. La justicia comunal se vuelve horizontal y pierde la jerarquía que determina la justicia formal.

Como vemos, la iglesia de Ocongate fue una fuerza externa decisiva en la conformación de la ronda campesina. Por ello, las plegarias religiosas al Dios cristiano se hallan presentes en todas las asambleas y actos públicos de las rondas. Pero, Jesucristo no está solo, sino que lo acompañan un conjunto de Apus, lugares sabios que residen en los nevados y cuya sapiencia es invocada con frecuencia en el desarrollo de las asambleas. De este modo, se produce una simbiosis espiritual, que comienza en el Dios cristiano y se abre a las creencias andinas tradicionales. 


\section{B. La evolución de las relaciones entre las rondas campesinas de Ocongate y las autoridades del estado a nivel local}

Hemos visto que las relaciones iniciales de las autoridades distritales del Estado fueron muy tensas, con las rondas campesinas. Los niveles de coordinación eran escasos y los choques fueron frecuentes. Se trataba del despliegue de dos sistemas de administración de justicia sobre el mismo territorio. Asimismo, se constata la presencia de dos sistemas de autoridades y personas concretas que pretenden representar la misma función. La contradicción era evidente y marcó los primeros años de la existencia de la ronda, esta afirmación nuestra es contrastable con los diversos cuadernos de actas de las rondas campesinas de Ocongate de los años 1995 al 2000 .

Durante este lapso, ambos sistemas se ignoraron recíprocamente. Las rondas fueron un tanto más amables como organización que estaba naciendo y se dirigían con respeto a las autoridades locales del Estado. Por ejemplo, las rondas invitaban a los jueces de paz y a los policías a las asambleas y plenarias que realizaban las rondas. Sin embargo, éstos no asistían y los ronderos se acostumbraron a funcionar sin la presencia de los agentes estatales. Esta tención continúa y de cuando en cuando estalla en algún conflicto. Pero ha disminuido en intensidad y, desde el año 2000, es perceptible una mayor colaboración entre ambos sistemas. De este modo, sin haber desaparecido los conflictos, ambos sistemas estarían empezando a convivir, habiendo aprendido a combinar sus habilidades y responsabilidades específicas, así consta en los diversos oficios cursados entre las rondas campesinas y los jueces de paz de Ocongate que se ha podido encontrar durante los trabajos de campo en los archivos de la central de rondas campesinas.

De acuerdo a Mariano Chillihuani, las rondas campesinas trabajan en forma coordinada con los jueces de paz, mientras que no tienen ninguna relación con la Policía Nacional. Los agentes armados del Estado serían más renuentes a la ronda campesina, sin embargo, ella siempre ha invitado a la Policía Nacional del Perú a sus diversas reuniones tal como se demuestra con los oficios hallados en los archivos de la ronda campesina de Ocongate. Por su parte, los jueces de paz son individuos de procedencia campesinas, normalmente parte de una pequeña elite local y están mejor dispuestos a entrar en relación con la ronda campesina.

Según Mariano Chillihuani, los jueces de paz actualmente suelen solicitar a las rondas campesinas que aplique disciplina a tal o cual delincuente que ellos han juzgado. Esta declaración se confirma con la opinión de Julián Rojo, quien reflexiona sobre la capacidad de la ronda para ejecutar sanciones decididas por los jueces de paz, quienes hasta ayer solo disponían de la Policía Nacional como fuerza coercitiva. Así, la ronda campesina seria ejecutor de las sanciones acordadas por el sistema formal de justicia. Esta información ha sido contrastada por los diferentes oficios encontrados en los archivos de la ronda de Ocongate donde efectivamente los jueces de paz demandan la ayuda de las rondas campesinas.

El mismo juez de paz del distrito de Ocongate, don Luis Alvarado (juez de paz Ocongate en el año 2008), lleva adelante una correspondencia con la central de rondas campesinas. A través de esta documentación se puede observar como el juez de paz intercambia información y deriva casos, para que la ronda "ajusticie" al delincuente, según sus propias palabras (Alvarado, comunicación personal, 27 de septiembre del 2008). El juez de paz habría buscado complementar su trabajo con las rondas, permitiendo que estas apliquen sanciones y realicen investigaciones, reservándose para sí la tarea de decidir los procesos judiciales. De una manera espontánea el juez de paz habría buscado colocarse como cabeza de la administración de justicia local coordinado con las rondas para una efectiva justicia local.

\section{Conclusiones}

Las rondas campesinas de Ocongate muestra un panorama general partiendo de casos anteriores situados en otras regiones del país, para poder tratar en detalle el caso específico de las rondas campesinas de un distrito 
de Ocongate, donde existe una compleja administración de justicia a partir de las propias comunidades campesinas.

Como antecedente de la ronda campesina, haciendo una historia comparada de las rondas campesinas de Ocongate y la historia de las rondas campesinas de Chota en Cajamarca; sobre sus antecedentes; hay una diferencia notoria, en cuanto a los personajes ó instituciones que existieron en defensa del campesino.

La parroquia como agente externo jugó un papel preponderante en la capacitación, orientación y asesoría para la formación de la ronda campesina mediante sus instituciones.

La situación de violencia que vivía el país en aquel entonces que básicamente era, los conflictos sociales ocasionados por el terrorismo, y este hecho del terrorismo fue aprovechado hábilmente por los abigeos y delincuentes para hacerse pasar por terroristas, es decir la delincuencia disfrazado de terrorismo.

La ronda campesina en su inicio tuvo una relación bastante difícil con las autoridades representativas del gobierno como, la PNP, el Juzgado de Paz, la Gobernatura entre otros. La reacción fue de rechazo aduciendo puntualmente que las rondas campesinas estaban cometiendo usurpación de funciones.

La ronda campesina tránsito de lo mono funcional a multifuncionales. Al inicio su función fue estrictamente lucha contra el abigeato, pero posteriormente empezó asumir nuevas funciones, gracias al prestigio social que ha adquirido.

La coexistencia de dos sistemas de justicia, Los jueces de paz actualmente suelen solicitar a las rondas campesinas que aplique disciplina a tal o cual delincuente que ellos han juzgado. Quienes hasta ayer solo disponían de la Policía Nacional como fuerza coercitiva. Así, la ronda campesina seria ejecutor de las sanciones acordadas por el sistema formal de justicia. De esta manera el juez de paz habría buscado complementar su trabajo con las rondas, permitiendo que estas apliquen sanciones y realicen investigaciones, reservándose para sí la tarea de decidir los procesos judiciales. De una manera espontánea el juez de paz habría buscado colocarse como cabeza de la administración de justicia local coordinado con las rondas para una efectiva justicia local.

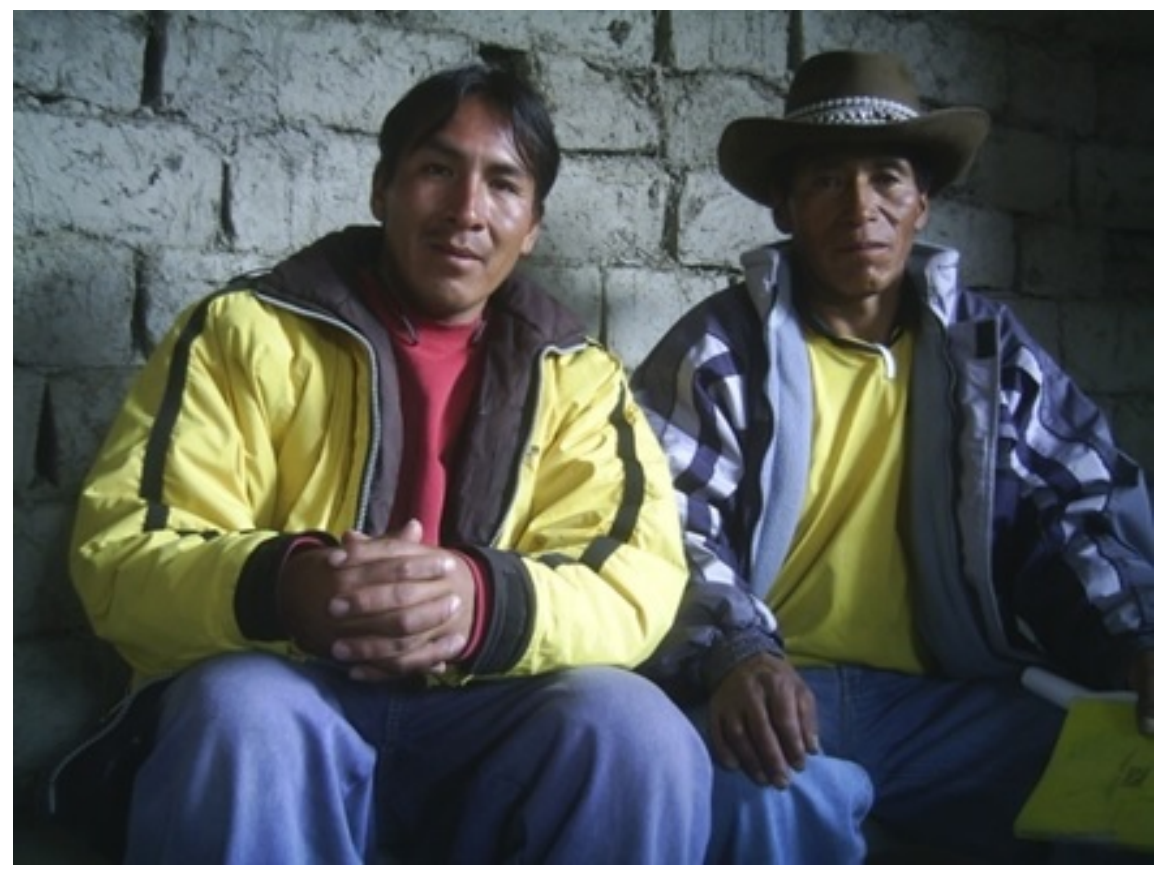

Julián Rojo Gonzalo 

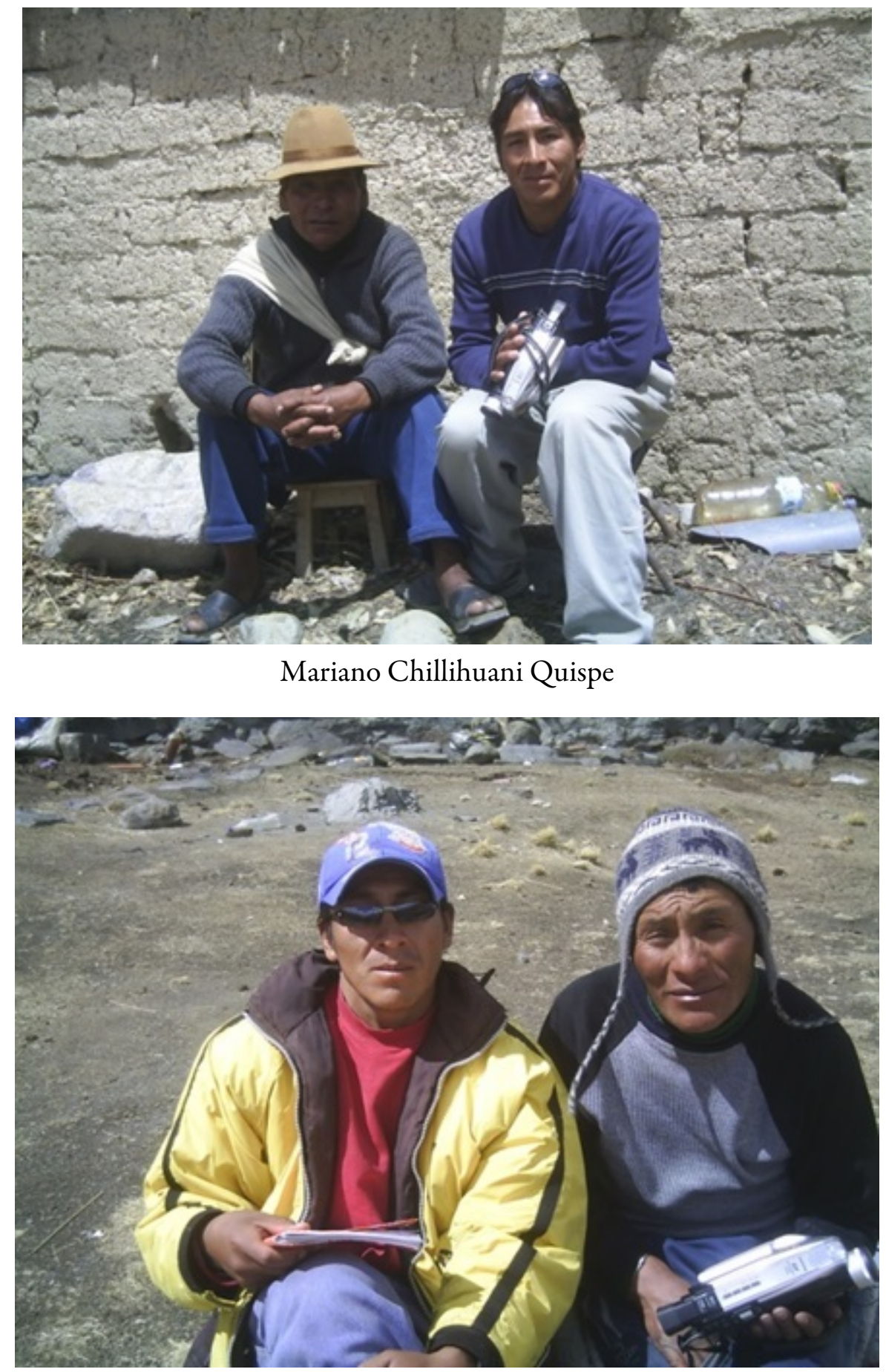

Julián Huamán Quispe 




Egidio Huanca Quispe y Toribio Mendoza Manani

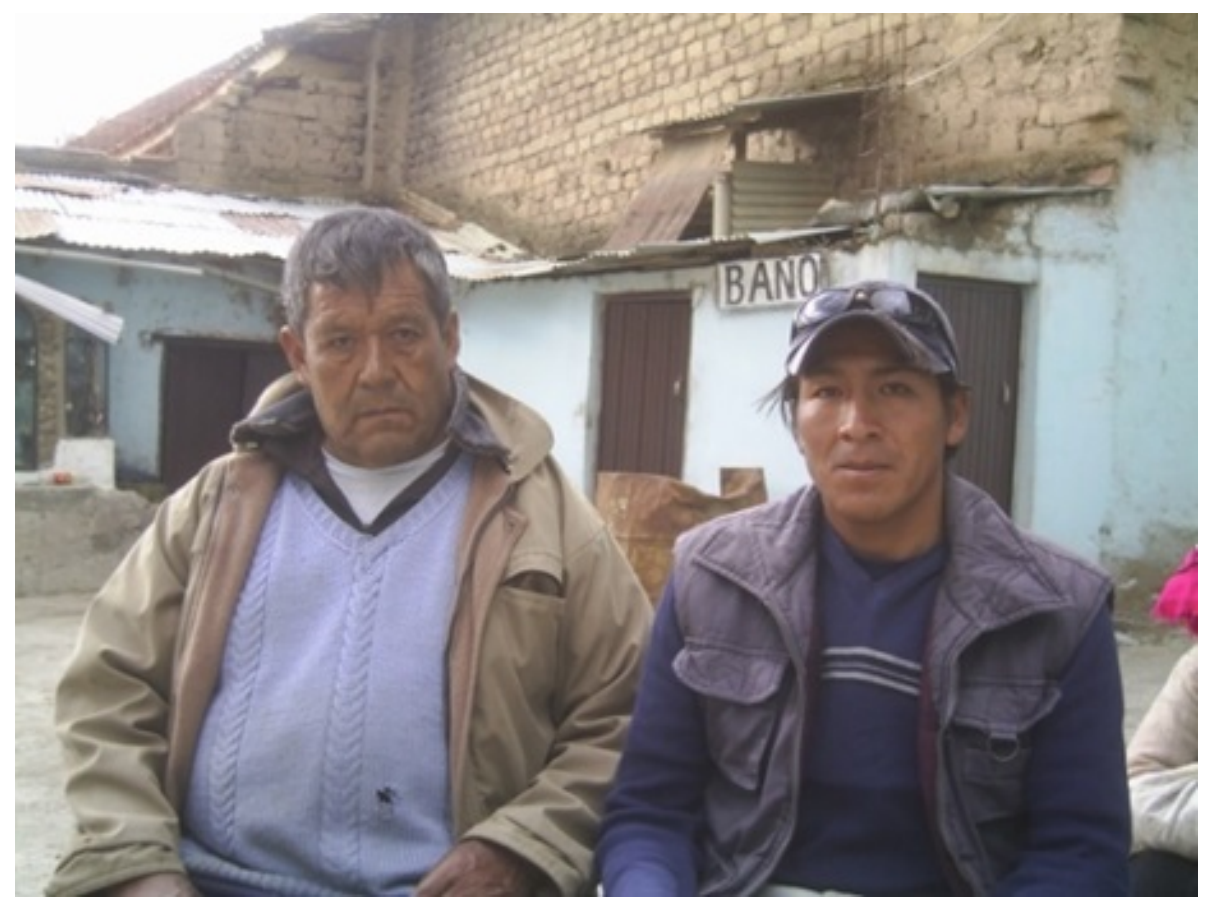

Luis Alvarado, juez de paz de Ocongate 2008 


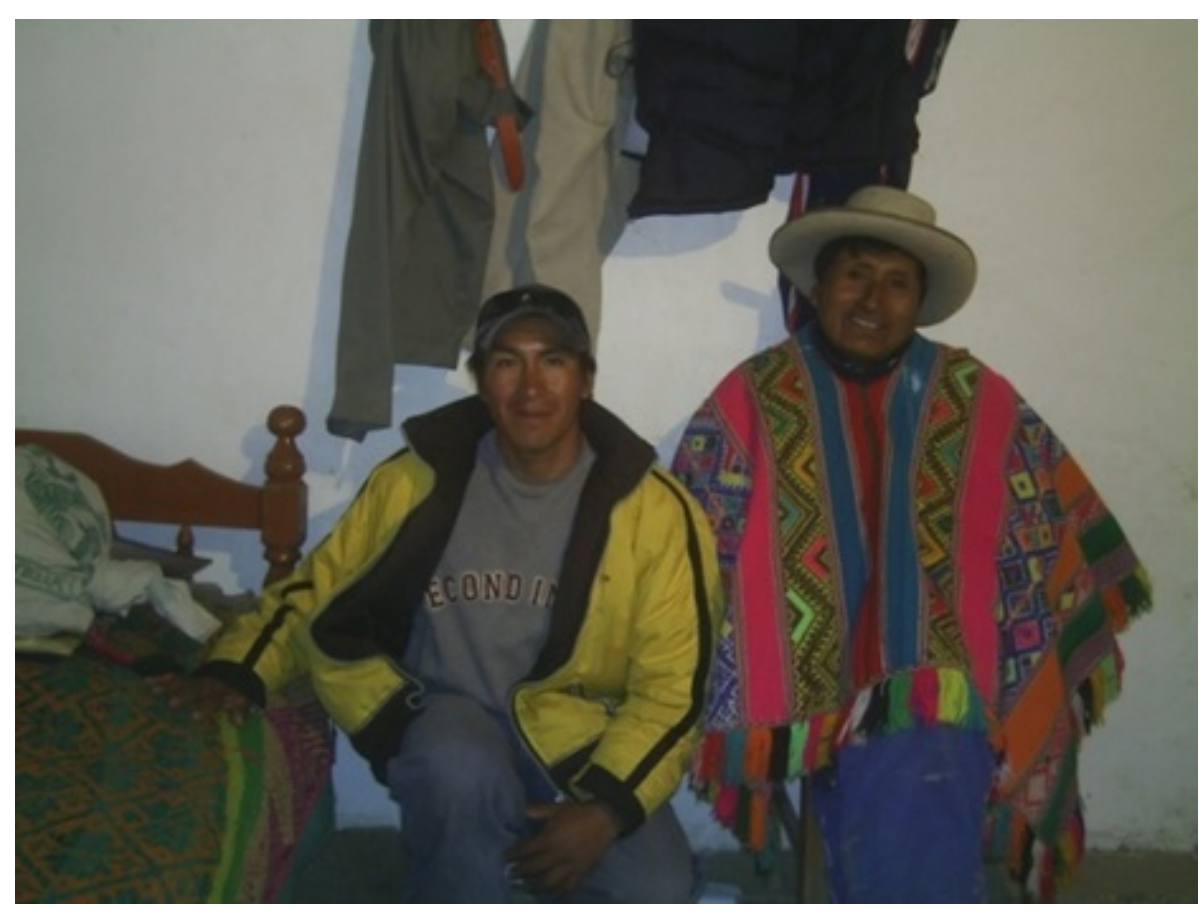

Hilario Quispe Mayo

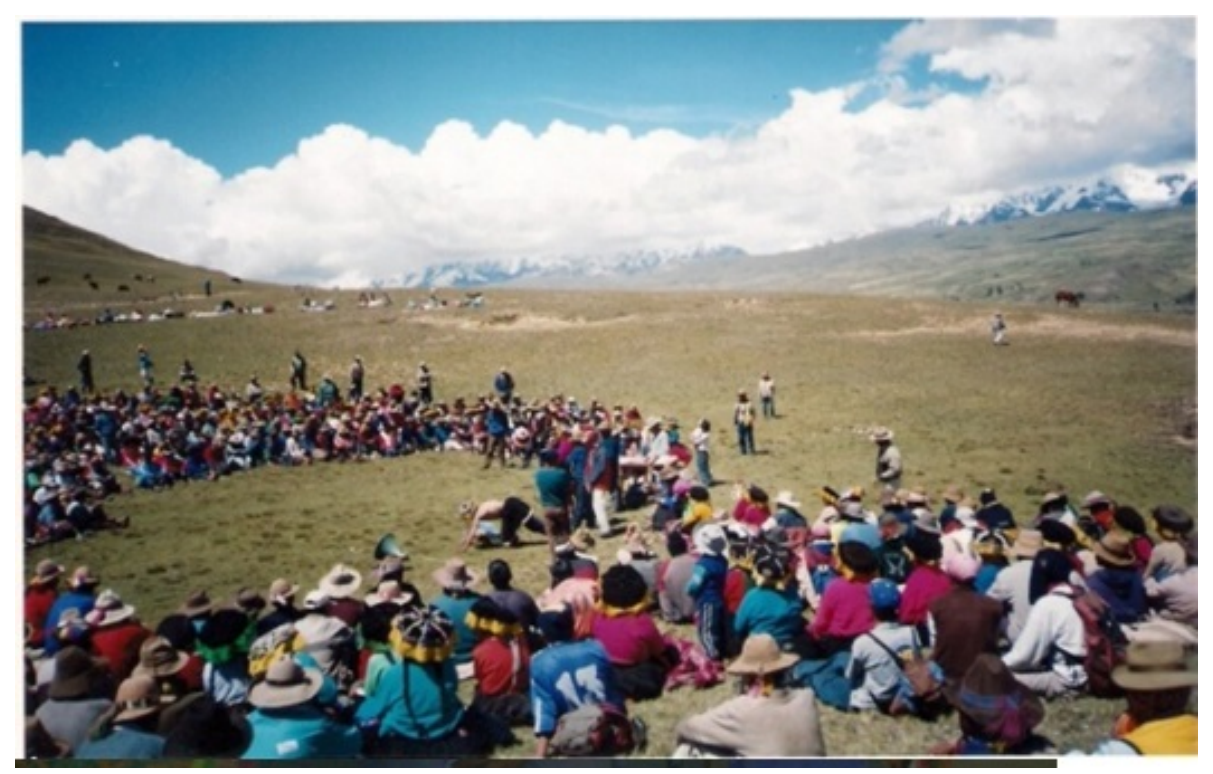

Delincuente vestido de mujer esta vez haciendo unos ejercicios físicos (planchas) en medio de la plenaria. Fuente: archivo fotográfico personal

\section{REFERENCIAS BIBLIOGRÁFICAS}

Aranda, M. (2004). Las rondas campesinas en las provincias altas del Cusco. Lima: Instituto de defensa legal IDL, PUCP y Asociación de jueces para la justicia y democracia.

Berrio, B. V., (2004). Nueva legislación y estatuto de comunidades campesinas. Lima: Editorial BERRIO.

Bonilla, J., Martines, A. (1995). Rondas campesinas: seguridad, resolución de conflictos y sistema de administración de justicia en comunidades de Cusco. Lima: SEPIA.

Bonifaz, N. (1986). Rodando la democracia. Seminario de investigación de la región norte. Cajamarca. 
Canal, J. (2001). Jueces Andinos. Cusco. Editorial POZO

CBC (2005). Las rondas campesinas en el sur andino del Perú. Cusco: CBC.

Chillihuani, V. (2008). Entrevistas.

Chillihuani, V. (2006). "Las rondas campesinas de Ocongate”. Riqchari Nº 01. Págs. 21 al 25. Cusco.

Guardamino, A. (1997). "Rondas campesinas de Ocongate”. El Chaski. N 02. Págs. 6 al 8. Andahuaylillas-Cusco. Boletín de la parroquia "San pablo de Apóstol" de Andahuaylillas.

Gitlitz, J. (1998). "Decadencia y supervivencia de las rondas campesinas del norte del Perú". Revista Debate Agrario $\mathrm{N}^{\circ} 28$. Págs. 23 al 53. Lima.

Libro De Cajas De La Ronda Campesina De Ocongate, legalizado por el juez de paz de primera nominación del distrito de OCONGATE, el 10 de junio 1994, consta de 100 folios. Tinky-Ocongate.

Libro De Actas De La Ronda Campesina De Ocongate, legalizado por el juez de paz no letrado del distrito de OCONGATE, el 05 de mayo 1995, consta de 100 folios. Tinky-Ocongate.

Libro De Actas De La Ronda Campesina De Ocongate, legalizado por el juez de paz no letrado del centro poblado de LAURAMARCA, el 06 de marzo 1996, consta de 400 folios. Tinky-Ocongate.

Libro De Actas De La Ronda Campesina De Ocongate, legalizado por el juez de paz no letrado del distrito de OCONGATE, el 13 de febrero 2000, 2002 y 2004 consta de 200 folios. Tinky-Ocongate.

Marquez, J. (1994). Ronderos los Ojos de la Noche. Lima: Instituto de defensa legal IDL.

Oficina Registral Regional Región Inka, Fecha: 11/25/97, Tomo: Leg-47, Asiento: 15591, Ficha Na: 1929, Denominación: Comité Central De Rondas Campesinas Del Distrito De Ocongate Y Carhuayo. Cusco.

Pérez, J. (1996). Rondas Campesinas Poder, Violencia y Autodefensa en Cajamarca Central. Lima: IEP.

Pérez, J. (1996). Montoneras, Bandoleras y Rondas Campesinas. Cajamarca: IEP

Reglamento De Rondas Campesinas (1988). Federación provincial de rondas campesinas de Cajamarca. Chota. Ediciones: Nuevo Curso.

Rojas, T. (1989). Rondas, poder campesino y el terror. Piura: Universidad Nacional de Cajamarca.

Starn, O. (1993). Hablan los ronderos la búsqueda de la paz en los andes. Lima: IEP.

Starn, O. (1991) Reflexionas sobre rondas Campesinas Protesta Rural y Nuevos Movimientos Sociales. Lima: IEP.

\section{Entrevistas}

ALVARADO, Luis. Juez de Paz del distrito de Ocongate en el año 2008 y poblador del distrito antes mencionado. Entrevista realizada el 27 de septiembre del 2008 en el distrito de Ocongate.

CHILLIHUANI QUISPE, Mariano. Edad 50 años de la comunidad de Huayna Ausangate y catequista de la parroquia de Ocongate. Presidente de la ronda campesina de central de Ocongate en el año 2000. Entrevista realizada en el centro poblado de Tinki del distrito de Ocongate a los 28 días del mes de septiembre del 2008.

HUANCA QUISPE, Egidio. Edad 47, de la comunidad campesina de Puca Orqo y catequista de la parroquia de Ocongate. Presidente de la ronda campesina central de Ocongate desde 2005. Entrevista realizada el 06 de septiembre del 2008 en el distrito Ocongate

HUAMAN QUISPE, Julián. Edad 49 años, de la comunidad campesina de Puyca distrito de Marcapata. Líder campesino y miembro de la primera junta directiva de la ronda campesina de Ocongate. Entrevista realizada en el anexo Yanacancha de la comunidad de Puyca, distrito Marcapata, en la fecha de 08 de septiembre del 2008.

GUARDAMINO SEMANTE, Antonio Sánchez. Párroco de la Iglesia de Ocongate de la orden de los jesuitas. Edad 65 años de nacionalidad extranjera que radica en Ocongate desde 1985 para adelante. Entrevista realizada en Ocongate, 08 de octubre del 2008. 
QUISPE MAYO, Hilario. Edad 49 años. Pastor evangélico de la comunidad cristiana de Tinki (Ocongate) y comunero de la comunidad campesina de Ausangate (Ocongate). Presidente de la ronda campesina central de Ocongate en el año 2008. Entrevista realizada el 24 de septiembre de 2008

MENDOZA MAMANI, Toribio, edad 44 años. De la comunidad campesina de Casapata, distrito de Carhuayo. Es miembro fundador de las rondas campesinas de Ocongate y presidente en el año 1998. Entrevista realizada en la fecha 06 de septiembre de 2008.

ROJO GONZALO, Julián. Edad 57, líder campesino de la comunidad campesina de Ausangate y presidente de la primera junta directiva de la ronda campesina de Ocongate. Entrevista realizada el 28 de agosto del 2008 en el Centro Poblado de Tinki.

Los autores otorgan el permiso a compartir y usar su trabajo manteniendo la autoría del mismo.

CC BY-NC 